\title{
Effect of Agglomeration on Technical Efficiency of Small and Medium-Sized Garment Firms in Egypt
}

\author{
Kenichi Kashiwagi and Erina Iwasaki*
}

\begin{abstract}
This study investigates the effects of agglomeration on the technical efficiency of small and mediumsized garment firms in Egypt. Using a sample of 502 firms, we estimated a translog stochastic frontier production function with inefficiency components. We also applied a switching regression model to address self-selection in choice of agglomeration. Results confirm that agglomeration enhances technical efficiency among sampled firms through development of industrial linkages and accumulation of human capital. Given the increasing importance of cluster-based development policies, we underscore the need to promote agglomeration of garment firms, and thereby foster forward and backward linkages to improve their efficiency and to develop global value chains.
\end{abstract}

\section{Introduction}

Developing economies are recognizing the significance of small and medium-sized enterprises (SMEs) for industrial development, and endorsing the advantages of agglomeration. In the Middle Eastern and North African (MENA) countries, Egypt is a typical example where SMEs agglomerate. Some clusters are created by the government as industrial zones and others have emerged without direct government intervention. Various industrial clusters have emerged such as textile, furniture, medical and aromatic plants (Abdelaziz et al., 2018). Regarding textile industry, Alexandria, Gharbia, Sharqia, Qalyubia, and Giza are notable for agglomerations of spinning and weaving firms, and garment firms have agglomerated in Alexandria, Cairo, Gharbia, Qalyubia, and Giza (CAPMAS, 2017).

In the wake of the Egyptian revolution of 2011, policy makers began to focus on the role of SMEs to recover from the subsequent economic crisis. While the stagnation of SMEs is one of major difficulties associated with the revolution (Assaad and Krafft, 2015), their potential becomes increasingly important for employment creation and development of global value chains (Galal, 2011; Loewe, 2015). After the revolution, two national strategies pursued: the 2015 Sustainable Development Strategy: Egypt's Vision 2030 and the 2017 Industry and Trade Development Strategy 2016-2020. The former sought to develop industrial clusters of SMEs, ${ }^{1}$ including the textile industry, through investment spanning 2014/2015-2018/2019 (Government of Egypt, 2015). The latter, especially its project of Environmentally Friendly Industrial Clusters, promoted development of 22 integrated industrial clusters, including textiles and ready-made garments. ${ }^{2}$ Under these national strategies, the roles of SMEs and cluster-based industrial development are becoming more crucial in the medium- and long-term.

Nonetheless, Egypt suffers from 'missing middle syndrome' and little industrial linkage among enterprises (Ministry of Finance, 2004). Egypt's 2012/2013 Economic Census indicated that 96.9\% of all manufacturing establishments employed fewer than 10 workers, as did $88 \%$ of firms in the textile and garment industry. Mediumsized enterprises accounted for a negligible percentage of distribution (CAPMAS, 2013). Moreover, most Egyptian firms participate in upstream production of low value-added activities, which impedes access to global production networks (Foster-McGregor et al., 2015; Del Prete et al., 2017). In the textile and garment industry, raw cotton is a major export product, but export of high value-added garments lags. Absence of a strong SME sector and poor industrial linkages constrain industrial competitiveness (Ministry of Finance, 2004).

Given these conditions, the objective of this study is to examine the effects of agglomeration on the firm-level technical efficiency (TE) of small and medium-sized garment firms in Egypt. Following Battese and Coelli (1995), we employ a stochastic frontier production (SFP) function with technical inefficiency components on a sample of 502 firms. We compare efficiency scores between agglomerated and non-agglomerated firms. Yet, we recognize that measured efficiency may be biased by self-selection in the choice of agglomeration. Thus, a possible selection bias may exist between the two groups. This selection bias can be mitigated by applying Heckman (1979) type of the twostage sample-selection procedures. We address potential self-selection by applying a two-stage method for switching regression models (Lee, 1978; Madalla, 1983).

\footnotetext{
* Kenichi Kashiwagi is an associate professor at Faculty of Humanities and Social Sciences, Alliance for Research on the Mediterranean and North Africa (ARENA), University of Tsukuba. Address: 1-1-1 Tennodai, Tsukuba, Ibaraki, 305-8571 Japan; Tel. +81-29-853-3982, Fax. +81-29-853-5776, e-mail kashiwagi.kenichi.fn@u.tsukuba.ac.jp. Erina Iwasaki is a professor at Faculty of Foreign Language, Sophia University. Address: 7-1 Kioi-cho, Chiyoda-ku, Tokyo 102-8554 Japan; Tel: +81-3-3238-3953, Fax: +81-42-592-3510, e-mail iwasaki@sophia.ac.jp
} 
This study assumes that agglomeration has a positive impact on TE. The positive spillover from agglomeration, such as the accumulation of human skills and the development of industrial linkage, are major factors associated with higher efficiency. Empirical evidence from Egypt is relevant to other countries suffering from missing middle syndrome and absence of a strong private sector. After the Arab revolution, economies of Egypt and other Arab countries have been precarious and stagnating (Springborg, 2011). Even if revolution replaces an old regime, the result might merely reconfigure political power and leave economic structure unaltered. New regimes need to develop the private sector to generate revenue streams other than oil, aid, and remittances (Malik and Awadallah, 2013). In this context, our study implies that fostering industrial clusters through agglomeration of SMEs is a significant remedy for missing middle syndrome and lack of a strong private sector.

This study proceeds as follows. Section 2 reviews literature. Section 3 describes our models and Section 4 describes our survey and data collection. Section 5 presents empirical results, followed by discussions in Section 6 . Section 7 concludes and offers policy implications.

\section{Review of the Literature}

The advantages of agglomeration and the role of SMEs in promoting industrial development have been widely discussed. Sonobe and Otsuka (2006) comprehensively discussed the historical development of industrial clusters in East Asia. Based on the Asian experience, Akoten and Otsuka (2007), and Sonobe and Otsuka (2011) extended the investigation to sub-Saharan Africa. These studies confirm the merits of agglomeration and positive effects of its externalities. More recently, Fukunishi and Yamagata (2014) made a comprehensive study of the garment industry in Asia and Africa, which focuses on its dynamism under trade liberalization.

Regarding the effect of agglomeration on efficiency, Tveteras and Battese (2006) found positive agglomeration externalities on TE of salmon aquaculture. Larue and Latruffe (2008) suggested positive externalities of agglomeration on efficiency of pig farms in France. For automobile component industries of Chennai in India, Bhaskaran (2012) found a significant increase in TE due to agglomeration. Agovino and Rapposelli (2015) found a positive impact of localization and urbanization on TE in 20 regional Italian economies. In manufacturing sector of Korea, Choi and Choi (2017) confirmed a positive impact of agglomeration on productivity and employment growth. Fafchamps and El-Hamine (2017) suggested that agglomeration externalities occur for productivity of manufacturing in Morocco. For manufacturing firms in Kenya, Cheruiyot (2017) found firms located in capital city associate with higher efficiency.

Few studies examined agglomeration effects of Egyptian manufacturers. Chaffai et al. (2012) examined factors that affect TE of Egyptian textile firms. This study did not quantify the agglomeration effect, but found a positive impact of the in-house and external business environment. Abdelaziz et al. (2018) mapped Egypt's most promising industrial clusters, including ready-made garments. Using firm-level data in Egypt, Badr et al. (2018) documented the advantages of agglomeration for total factor productivity.

We employ a switching regression model to address potential bias from self-selection of agglomeration. Freeman et al. (1998) applied a switching model to analyze how access to credit impacts productivity of small-holder dairy farms in Ethiopia and Kenya. More recently, Sipiläinen and Lansink (2005) addressed selection bias of organic and conventional dairy farms in Finland for the estimation of TE. Using a sample of conventional and organic dairy farms in the US, Kumbhakar and Tsionas (2008) addressed endogeneity of technology choice by jointly estimating the technology choice and production frontier. Solís et al. (2007) applied a switching regression model to mitigate potential selectivity bias to estimate TE of hillside farmers in El Salvador and Honduras. Following Solís et al. (2007), we employ these two-stage procedures in the estimation, introducing the inverse Mills ratio estimated by a first-stage probit estimator into the SFP in a second stage. Sample selection is a potential issue due to the firms' choice of agglomeration; however, most studies did not modify selection bias in estimating SFP. Hence, few studies examined the impact of agglomeration on TE considering the endogenous decision of agglomeration.

\section{Model}

In this study, we employ a two-stage switching regression model. The decision on location choice (agglomerate or not agglomerate) is modelled by the standard limited dependent variable methods. The first-stage is to examine the factors affecting the location choice. Let the decision to agglomerate be a dichotomous choice resulting from profit maximization. The decision of the $i$ th firm to agglomerate is described by an unobserved selection criterion function $I^{*}$. It can be modelled as follows:

$$
I^{*}=\alpha^{\prime} Z_{i}+\mu_{o i},
$$

where subscript $i$ denotes $i$ th firm, $Z_{i}$ is a vector of exogenous variables; $\alpha$ is a vector of parameters to be estimated; $\mu_{o i}$ is a random disturbance term distributed with zero mean and variance $\sigma_{o}^{2}$. The error term includes measurement error and unobserved factors. Equation (1) assumes firms are heterogeneous in their characteristics, and not all firms 
consider agglomeration has merits. The selection criterion function is not observed; however, the observable is the dichotomous location choice $I$. It takes a value of 1 for agglomerated firms and 0 otherwise:

$$
\begin{aligned}
& I=1 \text { if } I^{*}=\alpha^{\prime} Z_{i}+\mu_{o i} \geq 0, \\
& I=0 \text { otherwise. }
\end{aligned}
$$

The second-stage is to estimate production function of the two groups of firms. In this method, the behaviour of firms is described by two regression models with an endogenous criterion function that determines which of these two equations are applicable (Maddala, 1983). Following Feder et al. (1990) and Freeman et al. (1998), production functions are specified separately for agglomerated and non-agglomerated firms:

$$
\begin{aligned}
& Y_{a i}=\beta_{a}^{\prime} X_{a i}+\mu_{a i} \quad \text { if } \quad I=1, \\
& Y_{n i}=\beta_{n}^{\prime} X_{n i}+\mu_{n i} \quad \text { if } \quad I=0,
\end{aligned}
$$

where $Y_{a i}$ and $Y_{n i}$ represent the output of agglomerated and non-agglomerated firms, respectively; $X_{a i}$ and $X_{n i}$ are vectors of exogenous variables; $\beta_{a}$ and $\beta_{n}$ are vectors of parameters to be estimated; $\mu_{a i}$ and $\mu_{n i}$ are random disturbance terms. Because of the endogeneity of choice of location, OLS estimates of $\beta_{a}$ and $\beta_{n}$ may cause a bias. Namely, the expected values of the disturbance terms, conditional on the sample-selection criterion, are non-zero (Madalla, 1983; Lee, 1978). In addition, Maddala (1983) argued that $\mu_{0 i}, \mu_{a i}$ and $\mu_{n i}$ are assumed to have a trivariate normal distribution with zero mean and a non-singular covariance matrix.

The estimation of Equations (1)-(4) using maximum-likelihood is feasible but complicated (Madalla, 1983). Hence, we follow Lee (1978) and Freeman et al. (1998) by using a two-stage estimation method, where selectivity bias is treated as a problem due to the missing variable. It is assumed that the error terms have a joint-normal distribution with the covariance matrix as follows:

$$
\operatorname{Cov}\left(\mu_{a}, \mu_{n}, \mu_{o}\right)=\left[\begin{array}{ccc}
\sigma_{a}^{2} & \sigma_{a n} & \sigma_{a o} \\
\sigma_{a n} & \sigma_{n}^{2} & \sigma_{n o} \\
\sigma_{a o} & \sigma_{n o} & \sigma_{o}^{2}
\end{array}\right],
$$

where $\operatorname{var}\left(\mu_{a}\right)=\sigma_{a}^{2}, \operatorname{var}\left(\mu_{n}\right)=\sigma_{n}^{2}, \operatorname{var}\left(\mu_{o}\right)=\sigma_{o}^{2}, \operatorname{cov}\left(\mu_{a}, \mu_{n}\right)=\sigma_{a n}, \operatorname{cov}\left(\mu_{a}, \mu_{o}\right)=\sigma_{a o}$ and $\operatorname{cov}\left(\mu_{n}, \mu_{o}\right)=\sigma_{n o}$. The expected values of the truncated error terms $\left(\mu_{a} \mid I=1\right)$ and $\left(\mu_{n} \mid I=0\right)$ in Equations (3) and (4) are:

$$
\begin{aligned}
& E\left(\mu_{a} \mid \mu_{o} \leq \alpha^{\prime} Z_{i}\right)=E\left(\sigma_{a o} \mu_{a} \mid \mu_{o} \leq \alpha^{\prime} Z_{i}\right)=\sigma_{a o} \frac{\varphi\left(\alpha^{\prime} Z_{i}\right)}{\Phi\left(\alpha^{\prime} Z_{i}\right)} \equiv \sigma_{a o} W_{a i}, \\
& E\left(\mu_{n} \mid \mu_{o} \geq \alpha^{\prime} Z_{i}\right)=E\left(\sigma_{n o} \mu_{o} \mid \mu_{o} \geq \alpha^{\prime} Z_{i}\right)=\sigma_{n o} \frac{-\varphi\left(\alpha^{\prime} Z_{i}\right)}{1-\Phi\left(\alpha^{\prime} Z_{i}\right)} \equiv \sigma_{n o} W_{n i},
\end{aligned}
$$

where $\phi$ is the probability density function; $\Phi$ is the cumulative distribution function of the standard normal distribution. The ratio, $\phi / \Phi$, evaluated at $\alpha^{\prime} Z_{i}$ for each $I$ denotes the inverse Mills ratio $\left(W_{a i}\right.$ and $\left.W_{n i}\right)$. These terms can be treated as missing variables as the self-selectively variables. The revised equations can be depicted as:

$$
\begin{gathered}
Y_{a i}=\beta_{a}^{\prime} X_{a i}+\sigma_{a o} W_{a i}+\varepsilon_{a i} \text { if } I=1, \\
Y_{n i}=\beta_{n}^{\prime} X_{n i}+\sigma_{n o} W_{n i}+\varepsilon_{n i} \text { if } I=0,
\end{gathered}
$$

where $\varepsilon_{a i}$ and $\varepsilon_{n i}$ are the residuals having zero conditional means. If the covariance terms $\sigma_{a o}$ and $\sigma_{n o}$ are non-zero, the estimators in Equations (3) and (4) may suffer from self-selection bias.

This methodology for adjusting self-selectivity bias can be applied to the SFP model (Solis et al., 2007; Rahman et al., 2009). Following the SFP framework (Aigner et al., 1977; Battese and Coelli, 1995; Lachaal et al., 2006), we postulate restricted translog SFP function as follows:

$$
\begin{aligned}
& \ln Y_{a i}=\beta_{a 0}+\sum_{j=K}^{M} \beta_{a j} \ln X_{a j i}+\frac{1}{2} \sum_{j=K}^{M} \sum_{k=K}^{M} \beta_{a j k} \ln X_{a j i} \ln X_{a k i}+\sigma_{a o} W_{a i}+v_{a i}-u_{a i} \text { if } \quad I=1, \\
& \ln Y_{n i}=\beta_{n 0}+\sum_{j=K}^{M} \beta_{n j} \ln X_{n j i}+\frac{1}{2} \sum_{j=K}^{M} \sum_{k=K}^{M} \beta_{n j k} \ln X_{n j i} \ln X_{n k i}+\sigma_{n o} W_{n i}+v_{n i}-u_{n i} \text { if } \quad I=0,
\end{aligned}
$$

where subscripts $j$ and $k$ represent inputs used for production $(j, k=K, L, M) ; Y_{a i}$ and $Y_{n i}$ denote the gross production value; $X_{a K i}$ and $X_{n K i}$ denote the capital stock; $X_{a L i}$ and $X_{n L i}$ total working hours of labor; $X_{a M i}$ and $X_{n M i}$ are the volume of intermediate inputs utilized in production; $v_{a i}$ and $v_{n i}$ refer to two-sided, random disturbance terms, assumed to be 
an independently and identically distributed; $u_{a i}$ and $u_{n i}$ represent one-sided, non-negative random disturbance terms, assumed to be an independently and identically distributed with half-normal distribution at zero mean.

We adopt a single-stage approach for the estimation of SFP with inefficiency effect component (Kumbhakar et al., 1991; Battes and Coelli, 1995). The technical inefficiency components $u_{a i}$ and $u_{n i}$ are specified as follows:

$$
\begin{aligned}
& u_{a i}=\delta_{a 0}+\sum_{h=1}^{H} \delta_{a h} F_{a h i}+e_{a i} \quad \text { if } \quad I=1, \\
& u_{n i}=\delta_{n 0}+\sum_{h=1}^{H} \delta_{n h} F_{n h i}+e_{n i} \text { if } \quad I=0,
\end{aligned}
$$

where $\delta_{a}$ and $\delta_{n}$ are vectors of the unknown parameters to be estimated; $F_{a h}$ and $F_{n h}(h=1,2, \ldots, H)$ are explanatory variables associated with technical inefficiency in production; $e_{a i}$ and $e_{n i}$ are random disturbance terms.

\section{Data}

We took data from the Egypt Textile Industry Survey 2010, jointly implemented by the Egyptian Research and Training Center and Hitotsubashi University between July and September 2010. The surveyed textile and garment firms are located in seven regions: Cairo and Port Said from the Urban Governorates, Giza and Beni Suef from Upper Egypt, and Sharqiya, Qalyubia, and Gharbiya from Lower Egypt. We selected firms randomly in proportion to their size and sub-industry. Respondents completed 1,200 questionnaires with the response rate of $83.4 \%$. We used the 2006 Establishment Census and editions of Annual Industrial Statistics Bulletin by the Central Agency for Public Mobilization and Statistics (CAPMAS) to categorize samples by firm size and type. We identified 49 firms in spinning, 547 in weaving, and 580 in finish processing. We concentrated on garment firms in finishing processing, which constitutes a sample of 512 firms. We dropped 10 observations from empirical estimation that were missing information about output, capital stock, or working hours.

Table 1 presents descriptive statistics of variables for the sample of 502 firms. In the first-stage probit model, the dependent variable is dichotomous, reflecting agglomeration. It takes a value of 1 if many neighboring firms engage in similar activities and 0 otherwise. Independent variables Semi-skilled labor and High-skilled labor, denote the proportion of semi-skilled and high-skilled labor among all employees, respectively. Technology represents the difference in level technology of machinery measured from 1 to 3 (1: traditional, 2: modern, 3: updated). Wage rate denotes wage rate per employee in Egyptian pounds, and Capital-labor ratio is capital stock per employee in Egyptian pounds. We transformed both variables into logarithms. Manager age denotes the age of the firm's manager. Operation years is the number of years a firm has been operating. Industrial linkage is a dummy that equals 1 if the firm has links with other firms and 0 otherwise. Domestic supply represents the proportion of inputs supplied domestically. Regarding size of firms, Dummy small-size equals 1 if the firm employs 5 to 49 workers and 0 otherwise. Dummy medium-size equals 1 if the number of employees is 50 to 99 and 0 otherwise, while Dummy large-size equals 1 if the number of employees exceeds 50 and 0 otherwise. We control for geographical location by including Dummy lower Egypt if firms locate in governorates of lower Egypt and 0 otherwise, and Dummy upper Egypt if firms locate in governorates of upper Egypt and 0 otherwise.

The dependent variable for second-stage estimation of SFP is Gross production in Egyptian pounds. For estimation, it is transformed to a logarithm. Value added was frequently used instead of gross output to estimate production functions for the garment industry if firms subcontract materials from a buyer (Bakht et al., 2009; Fukunishi, 2009). However, subcontract is not widespread in Egypt's garment industry. We also used intermediate inputs that include cost of inputs bought from other firms and the monetary value of inputs supplied from subcontractors. Thus, we do not have severe problem for measuring inputs and output, even if gross production is used for the output variable. The input variable Capital is capital stock in Egyptian pounds. Labor denotes total hours of labor devoted to production. Intermediate inputs denotes intermediate inputs for production measured in Egyptian pounds. We took logarithms of these three inputs. We added the variable Technology in the production function to control for differing technology levels. We hypothesize that this variable may affect output directly but not efficiency. In the inefficiency components, we included variables Semi-skilled labor, High-skilled labor, Capital-labor ratio, Operation years, and Industrial linkage. We added Firm density, which denotes the density of textile and garment firms in each governorate as measured by their number per square kilometer.

Figure 1 presents comparison of average level of gross production, capital stock and labor cost measured by thousand Egyptian pound between agglomerated and non-agglomerated garment firms. Similarly, the comparison of average of gross production per labor and wage rate measured by Egyptian pound is shown in Figure 2. Comparison of these variables show relatively higher performance of agglomerated firms. The $t$-test results indicate the differences between the two groups are statistically significant. These results suggest the average level of output, inputs and labor productivity are higher in agglomerated firms compared with non-agglomerated firms. 
Table 1: Descriptive statistics of the variables in the sample

\begin{tabular}{lrrrrrr}
\hline Variable & \multicolumn{2}{c}{ All } & \multicolumn{2}{c}{ Agglomerated } & \multicolumn{2}{c}{ Non-agglomerated } \\
& Mean & SD & Mean & SD & Mean & SD \\
\hline Gross production & 13.725 & 1.466 & 13.966 & 1.360 & 12.968 & 1.534 \\
Capital stock & 12.010 & 1.705 & 12.196 & 1.680 & 11.422 & 1.654 \\
Labor & 11.204 & 1.788 & 11.429 & 1.856 & 10.496 & 1.333 \\
Intermediate inputs & 13.016 & 1.687 & 13.267 & 1.585 & 12.227 & 1.762 \\
Technology & 2.030 & 0.666 & 2.134 & 0.633 & 1.702 & 0.666 \\
Semi-skilled labor & 0.877 & 0.184 & 0.901 & 0.147 & 0.801 & 0.255 \\
High-skilled labor & 0.508 & 0.276 & 0.497 & 0.269 & 0.543 & 0.296 \\
Wage rate & 8.839 & 0.632 & 8.864 & 0.652 & 8.759 & 0.558 \\
Capital-labor ratio & 8.615 & 1.178 & 8.658 & 1.144 & 8.481 & 1.275 \\
Operation years & 11.84 & 9.919 & 11.829 & 9.849 & 11.868 & 10.176 \\
Manager age & 44.68 & 10.130 & 44.958 & 9.748 & 43.818 & 11.249 \\
Industrial linkage & 0.305 & 0.461 & 0.315 & 0.465 & 0.273 & 0.447 \\
Domestic supply & 0.965 & 0.145 & 0.965 & 0.139 & 0.967 & 0.160 \\
Firms density & 1.620 & 1.147 & 1.630 & 1.113 & 1.585 & 1.253 \\
Dummy small-size & 0.779 & 0.415 & 0.745 & 0.436 & 0.884 & 0.321 \\
Dummy medium-size & 0.062 & 0.241 & 0.066 & 0.248 & 0.050 & 0.218 \\
Dummy large-size & 0.125 & 0.332 & 0.152 & 0.360 & 0.041 & 0.199 \\
Dummy lower Egypt & 0.277 & 0.448 & 0.325 & 0.469 & 0.124 & 0.331 \\
Dummy upper Egypt & 0.289 & 0.454 & 0.270 & 0.445 & 0.347 & 0.478 \\
Number of firms & 502 & & 381 & & 121 &
\end{tabular}

Figure 1: Comparison of gross production, capital stock and labor cost between agglomerated and nonagglomerated firms

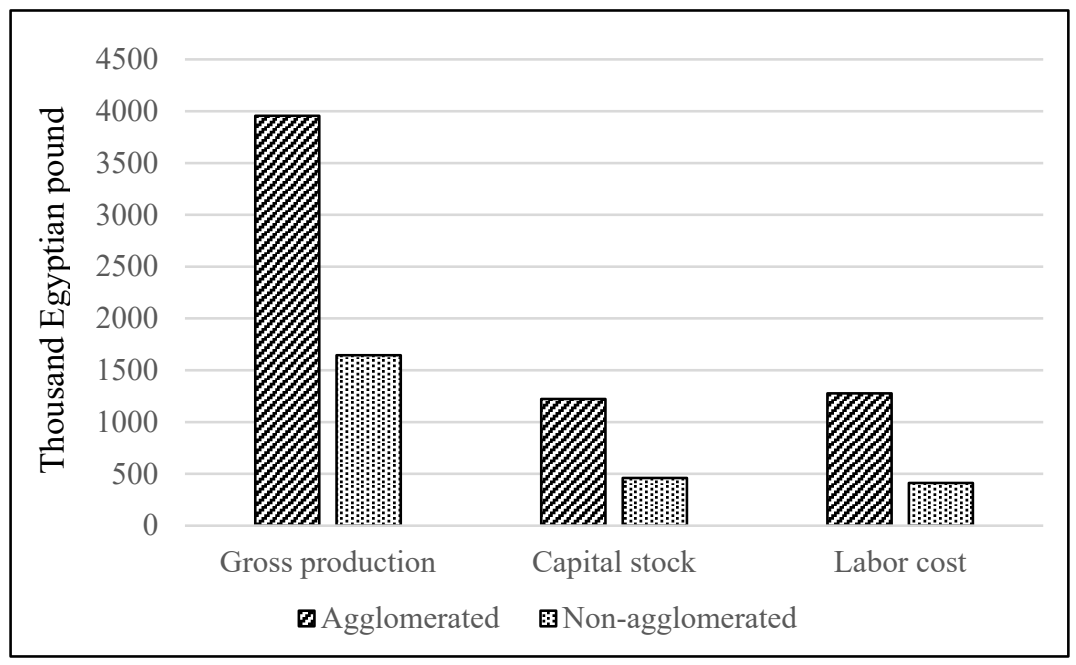


Figure 2: Comparison of gross production per labor and wage rate between agglomerated and nonagglomerated firms

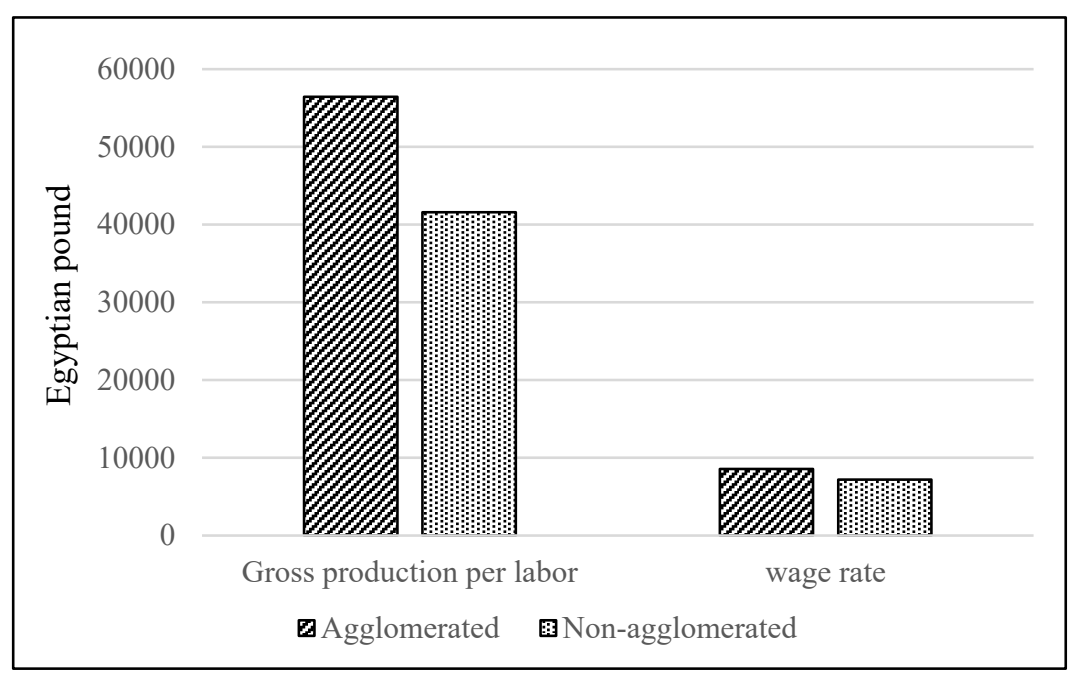

\section{Empirical Results}

Table 2 presents maximum likelihood estimates of the probit model and marginal effects (MEs) of respective explanatory variables. Following Madalla (1983), $\mathrm{ME}=\phi(\delta Z) \delta$, where $\phi$ is the probability density function, $Z$ the vector of explanatory variables and $\delta$ the estimated parameters. MEs are measured at the mean value of the regressors (Fuglie and Bosch, 1995; Freeman et al., 1998). We estimated MEs for the dummy variable as the difference between the value of the prediction when the explanatory variable equals 1 and when it equals to 0 (Solís et al., 2007). Chisquared statistics by a likelihood test with 14 degrees of freedom suggests significance at $1 \%$. Goodness-of-fit measures represented by the percentage of correct predictions indicate $77.5 \%$. The choice of independent variables correctly predicts firms' choice of agglomeration for $77.5 \%$ of the sample.

The estimated coefficient suggests firms that employ semi-skilled labor intensively will more likely to agglomerate. Agglomerated firms have more updated technology than non-agglomerated firms. We found a positive relation between the probability of agglomeration and having an industrial linkage. Firms located in industrial clusters are more likely to supply inputs from domestic producers. Access to human capital, technology, and industrial linkage significantly influence the probability of agglomerating. Variables denoting experience (years of operation and age of manager) do not influence the probability of agglomeration.

Table 3 displays second-stage estimates in the switching regression model. Three models of SFP with inefficiency components evaluate how agglomeration affects productivity. These models include self-selectivity variables $W_{\text {a }}$ and $W_{\text {na }}$ generated in the first stage of probit estimation. If their estimated coefficients are statistically significant, selectivity bias exists (Feder et al., 1990; Freeman et al., 1998; Solís et al., 2007). In estimations of Equations (10) and (11), the self-selectivity variables are included in the SFP, but the residuals are heteroscedastic. Therefore, we estimated these equations by weighted least squares to estimate the correct asymptotic covariate matrix and obtain robust estimates for standard errors (Lee, 1978; Fuglie and Bosch, 1995; Freeman et al., 1998; Solís et al., 2007).

We normalized all variables in the translog production function by their geometric means. Signs of estimated parameters of the translog SFP model are as expected. Estimated coefficients of capital stock and labor are positive and statistically significant in all models. These results indicate a positive relation between inputs of capital, labor and production of garment products. The coefficient of intermediate inputs is positive and statistically significant in models for all firms and agglomerated firms. Monotonicity conditions for capital, labor and intermediate inputs are satisfied in the three models. Those models also fulfill concavity conditions, where diminishing marginal productivities are negative for every input. The estimated parameter for the self-selectivity variable is negative and significant in the non-agglomerated model $\left(W_{\text {na }}\right)$, and not significant in the agglomerated model $\left(W_{\mathrm{a}}\right)$. These results suggest the sample of agglomerated firms suffers no serious sample-selection bias, but the statistically significant coefficient suggests it exists in the model of non-agglomerated firms. Thus, application of a sample-selection model in the estimation of SFP is justified to mitigate the sample-selection bias. 
Table 2: Estimated coefficients and standard errors of Probit selection equation

\begin{tabular}{lccr}
\hline Variables & Coefficient & SE & ME \\
\hline Constant & $-5.653^{* * *}$ & 1.728 & - \\
Semi-skilled labor & $2.442^{* * *}$ & 0.489 & 0.674 \\
High-skilled labor & -0.449 & 0.288 & -0.124 \\
Wage rate & 0.146 & 0.123 & 0.040 \\
Capital-labor ratio & -0.053 & 0.060 & -0.015 \\
Technology & $0.542^{* * *}$ & 0.121 & 0.150 \\
Operation years & -0.038 & 0.086 & -0.010 \\
Manager age & 0.294 & 0.320 & 0.081 \\
Industrial linkage & $0.277^{*}$ & 0.158 & 0.073 \\
Domestic supply & $1.794^{* * *}$ & 0.510 & 0.495 \\
Dummy small-size & $-0.734^{*}$ & 0.411 & -0.167 \\
Dummy medium-size & $-0.844^{*}$ & 0.511 & -0.292 \\
Dummy large-size & 0.105 & 0.511 & 0.028 \\
Dummy lower Egypt & $0.864^{* * *}$ & 0.221 & 0.199 \\
Dummy upper Egypt & $0.669^{* * *}$ & 0.188 & 0.162 \\
Likelihood ratio test $\left(\chi^{2}(14)\right)$ & & & \\
Percentage of correct predictions $(\%)$ & $101.2^{* * *}$ & & \\
Pseudo ${ }^{2}$ & 77.6 & & \\
Number of observations & 0.183 & 502 & \\
\hline
\end{tabular}

Note: $*{ }^{* *}, * * *$ indicate significant at the $10 \%$ level, $5 \%$ level, $1 \%$ level, respectively.

Estimated values of sigma-squared $\left(\sigma^{2}=\sigma_{v}{ }^{2}+\sigma_{u}{ }^{2}\right)$ are $0.506,0.362,0.583$ for all, agglomerated, and nonagglomerated firms, respectively. All are statistically significant at $1 \%$. The estimate of the variance parameter $\gamma(\gamma=$ $\sigma_{u}{ }^{2} / \sigma^{2}$ ) differs significantly from 0 at $1 \%$ in all three models. These results confirm the translog function is stochastic in all cases. Table 4 examines several hypotheses for the model's parameters using a log-likelihood test. This test was implemented by estimating log-likelihood ratio instead of using log-pseudo likelihood. Regarding the validity of specification of production function, the null hypothesis that $\beta_{j k}=0$ is rejected. This suggests the translog production function is more appropriate than the Cobb-Douglas form for Egyptian garment firms. We also rejected the null hypotheses that no inefficiency effects and no firm-specific factors explain technical inefficiency.

Estimated results of parameters among inefficient components are as expected. The coefficient of High-skilled labor is negative at $1 \%$ significance in three models and consistent with findings of a positive relation between human capital accumulation and efficiency (Ajibefun and Daramola, 2003; Solís et al., 2007; Rafman et al., 2009). The positive coefficient of Capital-labor ratio suggests capital-intensive firms are less efficient. The coefficient of Industrial linkage is negative and statistically significant at $1 \%$ for agglomerated firms, but it is not significant for non-agglomerated firms. This result suggests a positive relation between development of industrial linkages and efficiency. It is noteworthy that Firm density is negative and significant in all cases. This result suggests firms locate in governorates where textile and garment firms accumulated associate with higher efficiency. This result is consistent with Tveteras and Battese (2006), which found a positive effect for farm density on TE of the salmon industry. The coefficient of Operation years is negative and statistically significant for non-agglomerated firms. The positive effect of accumulation of experience on efficiency is only observed for non-agglomerated firms. The minor effect of firm age on TE is similar to the finding by Tveteras and Battesse (2006) in the salmon industry.

Table 5 displays estimations for the frequency distribution of TE. The average level of TE is $83.2 \%$, ranging from a minimum of $5.8 \%$ to a maximum of $99.3 \%$. Given present technology and inputs, Egyptian garment firms can increase production $16.8 \%$. This estimate of TE exceeds that of textile and garment firms in other countries: $54.9 \%$ in Kenya and Bangladesh (Fukunishi, 2009), 60.0\% for textile manufacturers in Kenya (Ngui-Munchai and Muniu, 2012), $77.4 \%$ to $82.9 \%$ for clothing and footwear manufacturers in Malawi (Chirwa, 2002), $50.3 \%$ and $50.6 \%$ for fabric knitters and garment makers in Bangladesh (Bakht et al., 2009), 63.0\% for Indonesia's garment industry (Hill and Kalirajan, 1993). The average level of TE of agglomerated firms is estimated at $87.0 \%$, while it is $71.3 \%$ for nonagglomerated firms. The $t$-test rejects at $1 \%$ the null hypothesis that the difference between the means of efficiency for these two groups equals 0 . This finding confirms the positive effect of agglomeration on TE for Egyptian garment firms. It is consistent with several empirical studies that suggest a positive effect of agglomeration on TE (Tveteras and Battese, 2006; Larue and Latruffe, 2008). 
Table 3: Estimated coefficients and robust standard errors of the translog stochastic frontier and inefficiency components

\begin{tabular}{|c|c|c|c|c|c|c|}
\hline \multirow[b]{2}{*}{ Variables } & \multicolumn{2}{|c|}{ All } & \multicolumn{2}{|c|}{ Agglomerated } & \multicolumn{2}{|c|}{ Non-agglomerated } \\
\hline & Coefficient & Robust SE & Coefficient & Robust SE & Coefficient & Robust SE \\
\hline \multicolumn{7}{|l|}{ Stochastic frontier model } \\
\hline Constant & $0.613^{* * *}$ & 0.144 & $0.578^{* * *}$ & 0.196 & 0.301 & 0.199 \\
\hline Capital & $0.279^{* * *}$ & 0.087 & $0.141^{* * *}$ & 0.039 & $0.268^{* * *}$ & 0.126 \\
\hline Labor & $0.181^{* * *}$ & 0.058 & $0.218^{* * *}$ & 0.027 & $0.400^{* * *}$ & 0.169 \\
\hline Intermediate inputs & $0.430^{* * *}$ & 0.045 & $0.530^{* * *}$ & 0.027 & 0.082 & 0.070 \\
\hline $0.5{\text { (Capital })^{2}}$ & 0.092 & 0.075 & 0.031 & 0.045 & $-0.121^{*}$ & 0.070 \\
\hline $0.5(\text { Labor })^{2}$ & $0.056^{* * *}$ & 0.019 & $0.047^{* * *}$ & 0.016 & $0.127^{*}$ & 0.074 \\
\hline $0.5{\text { (Intermediate inputs })^{2}}^{2}$ & $0.170^{* * *}$ & 0.031 & $0.156^{* * *}$ & 0.035 & $0.121^{* * *}$ & 0.032 \\
\hline Capital $\times$ Labor & -0.009 & 0.044 & -0.011 & 0.021 & 0.098 & 0.060 \\
\hline Capital $\times$ Intermediate inputs & $-0.090^{* *}$ & 0.036 & -0.030 & 0.029 & 0.044 & 0.033 \\
\hline Labor $\times$ Intermediate inputs & $-0.080^{* * *}$ & 0.029 & $-0.080^{* * *}$ & 0.017 & $-0.271^{* * *}$ & 0.043 \\
\hline Technology & 0.056 & 0.051 & 0.002 & 0.057 & 0.158 & 0.101 \\
\hline$W_{a}$ & - & - & -0.025 & 0.138 & - & - \\
\hline$W_{n a}$ & - & - & - & - & $-0.364^{*}$ & 0.219 \\
\hline \multicolumn{7}{|l|}{ Inefficiency components } \\
\hline Constant & $-5.887^{* * *}$ & 2.209 & $-8.203^{* * *}$ & 2.754 & $-5.723^{* *}$ & 2.405 \\
\hline Semi-skilled labor & 1.704 & 1.087 & 3.111 & 1.973 & 4.240 & 3.143 \\
\hline High-skilled labor & $-1.851^{* *}$ & 0.790 & $-2.547^{*}$ & 1.454 & $-4.846^{* *}$ & 1.923 \\
\hline Capital-labor ratio & $0.683^{* * *}$ & 0.245 & $0.567^{* *}$ & 0.222 & $0.669^{* * *}$ & 0.251 \\
\hline Operation years & -0.274 & 0.263 & 0.702 & 0.552 & $-0.676^{*}$ & 0.399 \\
\hline Industrial linkage & $-1.690^{* * *}$ & 0.362 & $-2.461^{* * *}$ & 0.906 & -0.603 & 0.702 \\
\hline Firms density & $-0.790^{* * *}$ & 0.294 & $-1.405^{* * *}$ & 0.455 & $-0.551^{*}$ & 0.318 \\
\hline \multicolumn{7}{|l|}{ Variance parameters } \\
\hline$\sigma_{v}$ & $0.378^{* * *}$ & 0.040 & $0.345^{* * *}$ & 0.034 & $0.319^{* * *}$ & 0.072 \\
\hline $\ln \sigma_{v}^{2}$ & $-1.946^{* * *}$ & 0.211 & $-2.129^{* * *}$ & 0.198 & $-2.283^{* * *}$ & 0.452 \\
\hline Log-pseudo likelihood & -11.327 & & -6.339 & & -2.749 & \\
\hline Number of observations & 502 & & 381 & & 121 & \\
\hline
\end{tabular}

Note: $*, * *, * * *$ indicate significant at the $10 \%$ level, $5 \%$ level, $1 \%$ level, respectively.

Table 4: Tests of hypotheses of the parameters of the stochastic frontier and inefficiency effect

\begin{tabular}{|c|c|c|c|}
\hline Models & Null Hypotheses & Log-likelihood ratio & Conclusion \\
\hline \multicolumn{4}{|l|}{ All } \\
\hline & Cobb-Douglas $\left(\beta_{i j}=0\right)$ & 93.697 & Reject $\mathrm{H}_{0}$ \\
\hline & No inefficiency effects $\left(\gamma=\delta_{i}=0, i=0,1,2,3 \ldots 6\right)$ & 70.927 & Reject $\mathrm{H}_{0}$ \\
\hline & No firm specific effects $\left(\delta_{i}=0, i=1,2,3, \ldots 6\right)$ & 67.226 & Reject $\mathrm{H}_{0}$ \\
\hline \multicolumn{4}{|c|}{ Agglomerated } \\
\hline & Cobb-Douglas $\left(\beta_{i j}=0\right)$ & 64.969 & Reject $\mathrm{H}_{0}$ \\
\hline & No inefficiency effects $\left(\gamma=\delta_{i}=0, i=0,1,2,3 \ldots 6\right)$ & 71.824 & Reject $\mathrm{H}_{0}$ \\
\hline & No firm specific effects $\left(\delta_{i}=0, i=1,2,3, \quad \ldots 6\right)$ & 69.504 & Reject $\mathrm{H}_{0}$ \\
\hline \multicolumn{4}{|c|}{ Non-agglomerated } \\
\hline & Cobb-Douglas $\left(\beta_{i j}=0\right)$ & 36.411 & Reject $\mathrm{H}_{0}$ \\
\hline & No inefficiency effects $\left(\gamma=\delta_{i}=0, i=0,1,2,3 \ldots 6\right)$ & 16.777 & Reject $\mathrm{H}_{0}$ \\
\hline & No firm specific effects $\left(\delta_{i}=0, i=1,2,3, \ldots 6\right)$ & 15.257 & Reject $\mathrm{H}_{0}$ \\
\hline
\end{tabular}


Table 5: Comparison of frequency distribution of technical efficiency between agglomerated and nonagglomerated firms

\begin{tabular}{lrrr}
\hline Technical efficiency (\%) & All & Agglomerated & Not agglomerated \\
\hline TE $<20$ & 5 & 3 & 2 \\
& $(1.0)$ & $(0.8)$ & $(1.6)$ \\
$20 \leq \mathrm{TE}<40$ & 9 & 6 & 3 \\
& $(1.8)$ & $(1.6)$ & $(2.5)$ \\
$40 \leq \mathrm{TE}<60$ & 29 & 3 & $(21.5)$ \\
& $(5.8)$ & $(0.8)$ & 41 \\
$60 \leq \mathrm{TE}<80$ & 111 & 70 & $(33.9)$ \\
& $(22.1)$ & $(18.3)$ & 49 \\
$80 \leq \mathrm{TE} \leq 100$ & 348 & 299 & $(40.5)$ \\
& $(69.3)$ & $(78.5)$ & 121 \\
Observations & 502 & 381 & 71.3 \\
Mean & 83.2 & 87.0 & 74.3 \\
Median & 89.3 & 91.3 & 18.6 \\
Standard deviation & 16.2 & 13.3 & 5.8 \\
Minimum & 5.8 & 13.1 & 99.1 \\
Maximum & 99.3 & 99.3 & \\
\hline
\end{tabular}

Note: Percentage is in parentheses.

\section{Discussions}

Similar to the findings by Tveteras and Battese (2006) and Larue and Latruffe (2008), we found that agglomeration has a positive impact on TE of Egyptian garment firms. Another important finding is that human capital accumulation has a positive effect on TE. These findings support Marshall (1920), which argues that industrial clusters offer positive effect of information spillover among firms and accumulation of skilled workers. In addition, we found that increased firm density associates with higher TE, echoing Tveteras and Battese (2006) which suggests greater firm density enhances TE through knowledge transmission. This finding implies that Egyptian garment firms could benefit from agglomeration through the dissemination of knowledge within industrial clusters.

While the rate of firms developed industrial linkages remained at $30.5 \%$ of our sample, it is an important factor associated with higher efficiency. The development of industrial linkage, including subcontracting arrangements, was observed in many clusters of Asian countries (Sonobe and Otsuka, 2006; Sonobe and Otsuka, 2011). In the case of Egypt, among firms established industrial linkages, the most common linkage is the marketing contract which represents $62.1 \%$, while only 18 firms $(11.8 \%)$ engage in subcontract. These figures suggest the forward linkage with customers seems to have relatively developed compared with the backward linkage with suppliers. Yet, only 72 of 502 sampled firms (14.3\%) have access to export markets. Among the firms with industrial linkages, only 26 firms $(17.0 \%)$ developed an export contract. These figures imply that the domestic consumer is a major market and that developing forward linkages may contribute to improve efficiency. However, expanding forward linkages to foreign customers remains challenging.

In general, production of low-quality goods targeting the domestic market is a major phenomenon during early stage industrial development. In this stage, producers try to produce standardised products to stabilize the production in quantity. However, in a more advanced stage, upgrading the quality of products becomes increasingly important in order to produce high-quality differentiated products (Sonobe and Otsuka, 2006). In such a stage, subcontract with long-term contracts in particular becomes crucial to exert the competitive advantage. As industrial development matures, manufacturers shift gradually from subcontracting to vertical integration of manufactures (Sonobe and Otsuka, 2011).

Reviewing the Asian experience, we infer that the pressure for quality assurance is weaker than that imposed by global consumers on Egypt's garment industry. Indeed, firms introduced quality control was only slightly more than half of our sample (51.6\%). As noted, we found even subcontract has been underdeveloped in the Egyptian garment industry. Indeed, Egyptian entrepreneurs are generally reluctant to cooperate with others, fearing that others might not fulfil their contracts (Loewe, 2015). In textile and garment industry, cooperation among firms is rare (Abdelaziz et al., 2018). In addition, a survey on Egyptian garment firms by El-Haddad (2008) suggests only $25 \%$ had integrated vertically because of financial constraints, limited firm size, desire to avoid risk, and monitoring costs.

Minimal subcontracting and vertical integration in Egypt's garment industry resemble the clothing industry in Lima (Peru) and Mexico's footwear industry (Visser, 1999; Rabellotti, 1995). However, competitive pressure on Egypt's garment industry has grown since phase-out of the Multi-Fibre Agreement in 2005. What is more, the 
development of global production networks has become increasingly important over time (Del Prete et al., 2017). Compliance with international standards has become sine qua non for entering global supply chains (Nadvi, 2008). Demands for greater local cooperation among producers, suppliers and subcontractors have escalated in response to quality requirements (Nadvi, 2008; Del Prete et al., 2017). Although subcontracting and vertical integration remain underdeveloped, our results imply that promoting agglomeration and enhancing industrial linkages would contribute to develop a global value chain of Egyptian garment industry.

\section{Conclusions and Policy Implications}

During the Arab socialist regime, the government of Egypt gave higher priority to the development of large enterprises. The planned economy favored development of large state-owned enterprises, which consequently, deterred development of a private sector generally and SMEs in particular. In this context, this study underlines the significance of a policy to develop the private sector through the agglomeration of SMEs. We found agglomerated firms realized higher TE than non-agglomerated. Human capital accumulation and establishing industrial linkages were the factors associate with higher efficiency. The relationship between density of firms and TE was positive. These findings suggest a positive effect of agglomeration on TE.

Notwithstanding the significance of industrial linkages, neither subcontract nor vertical integration is well developed among Egyptian garment firms. The lack of subcontract and vertical integration are impediments to boosting SMEs; however, we confirm the merit of agglomeration. Our finding of its positive effect on TE is empirical evidence for the effectiveness of on-going national strategies to promote industrial clusters. Accordingly, this study suggests two policy directions. The first is to promote forward linkages with firms in different processes of production. Namely, developing export contracts may contribute to improve the access to foreign markets and to expand the global value chain. Second, fostering backward linkages, including subcontract, can help to secure a supply of inputs by mitigating risks and uncertain of inputs in terms of quantity and quality. Consequently, promoting agglomeration, particularly fostering forward and backward linkages, could significantly improve SMEs' efficiency. Developing these industrial linkages would also encourage SMEs to develop global value chains.

\section{Notes}

1 See 'Sustainable Development Strategy (SDS): Egypt's Vision 2030'. <http://sdsegypt2030.com/?lang=en> (accessed: 23 May, 2019)

2 See Minister of Trade and Industry, 'Industry and Trade Development Strategy 2016-2020'. $<$ http://www.mti.gov.eg/English/MediaCenter/News/Pages/2017-Strategy.aspx> (accessed: 23 May, 2019)

\section{References}

Abdelaziz, F., El-Enbaby, H., Zhang, X. and Breisinger, C. (2018), 'Clusters as Drivers of Local Industrial Development in Egypt: Which are the Promising Sectors and Locations?', Middle East and North Africa Regional Program Working Paper 10, International Food Policy Research Institute (IFPRI), Washington, D.C.

Agovino, M. and Rapposelli, A. (2015), 'Agglomeration Externalities and Technical Efficiency in Italian Regions', Quality and Quantity, Vol. 49, 1803-1822.

Aigner, D.J., Lovell, C.A.K. and Schmidt, P. (1977), 'Formulation and Estimation of Stochastic Frontier Production Function Models', Journal of Econometrics, Vol. 6, No. 1, 21-37.

Ajibefun, I.A. and Daramola, A.G. (2003) 'Determinants of Technical and Allocative Efficiency of Micro-enterprises: Firm-level Evidence from Nigeria', African Development Review, Vol. 15, Issue 2-3, 353-395.

Akoten, J.E. and Otsuka, K. (2007), "From Tailors to Mini-manufactures: The Role of Traders in the Performance of Garment Enterprises in Kenya", Journal of African Economies, Vol. 16, No.4, 564-595.

Assaad, R. and Krafft, C. (2015), The Egyptian Labor Market in an Era of Revolution, Oxford University Press, Oxford.

Badr, K., Rizk, R. and Zaki, C. (2018), 'Firm Productivity and Agglomeration Economies: Evidence from Egyptian Data', Working Papers Series No. 1239, Economic Research Forum, Cairo.

Bakht, Z., Yamagata, T. and Yunus, M. (2009), 'Profitability and Diversity among Knitwear-Producing Firms in Bangladesh: The Prospects of a Labor-Intensive Industry in a Least Developed Country', Developing Economies, Vol. 47, No. 3, 340-366.

Battese, G.E. and Coelli, T.J. (1995), 'A Model for Technical Inefficiency Effects in a Stochastic Frontier Production Function for Panel Data', Empirical Economics, Vol. 20, No. 2, 325-332.

Bhaskaran, E. (2012), 'Technical Efficiency of Automotive Industry Cluster in Chennai', Journal of The Institution of Engineers (India): Series C, Vol. 93, Issue 3, 243-249.

Central Agency for Public Mobilization and Statistics (CAPMAS), Arab republic of Egypt (2013), Economic Census 
2012/2013, Cairo.

Central Agency for Public Mobilization and Statistics (CAPMAS), Arab republic of Egypt (2017), Establishment Census 2017, Cairo.

Chaffai, M, Kinda, T. and Plane, P. (2012), 'Textile Manufacturing in Eight Developing Countries: Does Business Environment Matter for Firm Technical Efficiency?', Journal of Development Studies, Vol. 48, No. 10, 14701488.

Cheruiyot, K.J. (2017) 'Determinants of Technical Efficiency in Kenyan Manufacturing Sector', African Development Review, Vol. 29, No. 1, 44-55.

Chirwa, E.W. (2002) 'Structural Adjustment Programmes and Technical Efficiency in the Malawian Manufacturing Sector', African Development Review, Vol. 12, Issue 1, 89-113.

Choi, M. and Choi, T. (2017), 'Agglomeration, Productivity, and High-growth Firms in the Manufacturing Sector of South Korea', International Journal of Urban Sciences, Vol. 21, Issue 1, 58-71.

Del Prete, D., Giovannetti, G. and Marvasi, E. (2017), 'Global Value Chains Participation and Productivity Gains for North African Firms', Review of World Economics, Vol. 153, Issue 4, 675-701.

El-Haddad, A. (2008), 'Vertical Integration and Institutional Constraint on Firm Behaviour: The Case of the Garment Industry in Egypt', Working Paper No. 383, Economic Research Forum, Cairo.

Fafchamps, M. and El-Hamine, S. (2017), 'Firm Productivity, Wages, and Agglomeration Externalities', Research in Economics, Vol. 71, Issue 2, 291-305.

Feder, G., Lau, L.J., Lin, J. and Luo, X. (1990), 'The Relationship between Credit and Productivity in Chinese Agriculture: A Microeconomic Model of Disequilibrium', American Journal of Agricultural Economics, Vol. 72, Issue 5, 1151-1157.

Foster-McGregor, N., Kaulich, F. and Stehrer, R. (2015), 'Global Value Chains in Africa', MERIT Working Papers 024, United Nations University, Maastricht Economic and Social Research Institute on Innovation and Technology (MERIT).

Freeman, H.A., Ehui, S.K. and Jabbar, M.A. (1998), 'Credit Constraints and Smallholder Dairy Production in the East African Highlands: Application of a Switching Regression Model', Agricultural Economics, Vol. 19, 33-44.

Fukunishi, T. (2009), 'Has Low Productivity Constrained the Competitiveness of African Firms? A Comparison of Kenyan and Bangladeshi Garment Firms', Developing Economies, Vol. 47, No.3, 307-339.

Fukunishi, T., and Yamagata, T. (2014) The Garment Industry in Low-Income Countries: An Entry Point of Industrialization, Palgrave Macmillan.

Fuglie, K.O. and Bosch, D.J. (1995), 'Economic and Environmental Implications of Soil Nitrogen Testing: A Switching-Regression Analysis', American Journal of Agricultural Economics, Vol. 77, Issue 4, 891-900.

Galal, A. (2011), 'Egypt Post January 2011: An Economic Perspective’, Policy Perspective No.3, Economic Research Forum, Cairo.

Government of Egypt (2015), Sustainable Development Strategy: Egypt's Vision 2030 and Medium Term Investment Framework 2014/2015 - 2018/2018, Cairo.

Heckman, J. (1979), 'Sample Selection Bias as a Specification Error', Econometrica, Vol. 47, No. 1, 153-161.

Hill, H. and Kalirajan, K.P. (1993), 'Small Enterprise and Firm-level Technical Efficiency in the Indonesian Garment Industry', Applied Economics, Vol. 25, Issue 9, 1137-1144.

Kumbhakar, S.C. and Tsionas, E.G. (2008), 'Joint Estimation of Technology Choice and Technical Efficiency: An Application to Organic and Conventional Dairy Farming', Journal of Productivity Analysis, Vol. 31, 151-161.

Kumbhakar, S.C., Ghosh, S. and McGuckin, J.T. (1991), 'A Generalized Production Frontier Approach for Estimating Determinants of Inefficiency in U.S. Dairy Farms', Journal of Business and Economic Statistics, Vol. 9, 279-286.

Lachaal, L., Karray, B. Dhehibi, B. and Chebil, A. (2006), 'Technical Efficiency Measures and Its Determinants for Olive Producing Farms in Tunisia: A Stochastic Frontier Analysis,' African Development Review, Vol. 17, No. 3, 580-591.

Larue, S. and Latruffe, L. (2008), 'Agglomeration Externalities and Technical Efficiency in Pig Production', paper presented at 12th Congress of the European Association of Agricultural Economists (EAAE 2008), Ghent, Belgium.

Lee, L.F. (1978), 'Unionism and Wage Rates: A Simultaneous Equations Model with Qualitative and Limited Dependent Variables', International Economic Review, Vol. 19, Issue 2, 415-433.

Loewe, M. (2015), 'Transforming Egypt: Innovation and Diversification as Drivers of Growth', ERF Policy Brief No. 1, Economic Research Forum, Cairo.

Madalla, G.S. (1983), Limited-Dependent and Qualitative Variables in Econometrics, Cambridge University Press, Cambridge.

Malik, A., and Awadallah, B. (2013), 'The Economics of the Arab Spring', World Development, Vol. 45, 296-313.

Marshall, A. (1920), Principles of Economics, 8th edition, Macmillan \& Co. Ltd., London. 
Matsunaga, N. and Vixathep, S. (2012), 'Technical Efficiencies of Garment Enterprises in Vietnam', Journal of Economic Policy Studies, Vol. 9, No. 1, 38-50.

Ministry of Finance, Arab Republic of Egypt (2004), Enhancing Competitiveness for SMEs in Egypt: General Framework and Action Plan, Cairo.

Nadvi, K. (2008), 'Global Standards, Global Governance and the Organization of Global Value Chains', Journal of Economic Geography, Vol. 8, Issue 3, 323-343.

Ngui-Muchai, D.M. and Muniu, J.M. (2012) 'Firm Efficiency Differences and Distribution in the Kenyan Manufacturing Sector', African Development Review, Vol. 24, No. 1, 52-66.

Rabellotti, R. (1995), 'Is there an "Industrial District Model"? Footwear Districts in Italy and Mexico Compared', World Development, Vol. 23, No. 1, 29-41.

Rafman, S., Wiboonpongse, A., Sriboonchitta, S. and Chaovanapoonphol, Y. (2009), 'Production Efficiency of Jasmine Rice Producers in Northern and North-eastern Thailand', Journal of Agricultural Economics, Vol. 60, No. 2, 419-435.

Sipiläinen, T. and Lansink, A.O. (2005), 'Learning in Organic Farming-An Application on Finnish Dairy Farms', paper presented at the XI Congress of the EAAE, Copenhagen, August 24-27.

Solís, D., Bravo-Ureta, B.E. and Quiroga, R.E. (2007), 'Soil Conservation and Technical Efficiency among Hillside Farmers in Central America: A Switching Regression Model', Australian Journal of Agricultural and Resource Economics, Vol. 51, 491-510.

Sonobe, T. and Otsuka, K. (2006), Cluster-based Industrial Development: An East Asian Model, Palgrave Macmillan: Houndmills, UK.

Sonobe T. and Otsuka K. (2011), Cluster-based Industrial Development: A Comparative Study of Asia and Africa, Palgrave Macmillan: Hampshire, UK.

Springborg, R. (2011), 'The Precarious Economics of Arab Springs', Survival, Vol. 53, Issue 6, 85-104.

Tveteras, R. and Battese, G.E. (2006), 'Agglomeration Externalities, Productivity, and Technical Inefficiency', Journal of Regional Science, Vol. 46, No. 4, 605-625.

Visser, E. (1999), 'A Comparison of Clustered and Dispersed Firms in the Small-scale Clothing Industry of Lima', World Development, Vol. 27, No. 9, 553-1570.

\section{Acknowledgement}

We gratefully acknowledge that this research was supported by the Japan Society for Promotion of Science (JSPS) Grants-in-Aid for Scientific Research of Young Scholars (A), No. 24683008 entitled: 'Research on Development of Local Industry by Valorization of Bio-resources in North Africa and Mediterranean Countries', and partially supported by Needs-Based Program for Area Studies: 'The Middle East within Asia: Law and Economics' sponsored by the Ministry of Education, Culture, Sports, Science and Technology. 